\title{
Incidence and predictors of new onset left ventricular diastolic dysfunction in asymptomatic patients with rheumatoid arthritis without overt cardiac disease
}

\author{
Elena Costanza dal Piaz', Giovanni Cioffi ${ }^{2}$, Federica Ognibeni², Andrea Dalbeni ${ }^{3}$, Alessandro Giollo ${ }^{2}$, \\ Giovanni Orsolini², Davide Gatti ${ }^{2}$, Luca Idolazzi ${ }^{2}$, Carlo Stefenelli ${ }^{1}$, Maurizio Rossini², \\ Ombretta Viapiana ${ }^{2}$
}

${ }^{1}$ Department of Cardiology, Villa Bianca Hospital, Trento; ${ }^{2}$ Rheumatology Unit, Department of Medicine, University of Verona; ${ }^{3}$ General Medicine and Hypertension Unit, Department of Medicine, University of Verona, Italy

\begin{abstract}
Rheumatoid arthritis (RA) is associated with higher risk of heart failure. Several studies report that left ventricular (LV) diastolic dysfunction (LVDD), a silent precursor of heart failure, is widely present in RA patients. Very little is known about the factors related to the development of LVDD in this disease. In this study we assessed the incidence and the predictors of new-onset LVDD in RA patients. Two-hundred-ninety-five adults with RA without overt cardiac disease were prospectively analyzed from
\end{abstract}

Correspondence: Giovanni Cioffi, Rheumatoloy Unit, Policlinico Borgo Roma, Piazzale Scuro 10, 37134 Verona, Italy.

Tel. +39.045.8121111.

E-mail: dottcioffi@gmail.com

Contributions: ECdP, GC, FO, OV, MR, study concept and design; GC, FO, AD, AG, GO, LI, OV, generation of clinical data; ECdP, GC, FO, GO, MR, OV, data analysis and interpretation; GC, responsible of the overall content of the manuscript. All the authors participated to the draft of the study protocol and gave a relevant contribution in the interpretation of the results suggesting important implementations in the statistical analysis process. All the authors critically reviewed the manuscript and approved its final version. All the authors take responsibility for all aspects of the reliability and freedom from bias of the data presented and their discussed interpretation.

Conflict of interest: The authors declare that that no conflict of interest exists (no relationship with industry or financial associations poses a conflict of interest in connection with the present study). No author received any financial support or other benefits from commercial sources for this work.

Key words: Left ventricular diastolic dysfunction; rheumatoid arthritis; heart failure; transthoracic Doppler echocardiography.

Received for publication: 20 February 2019.

Accepted for publication: 9 July 2019.

${ }^{\circ}$ Copyright: the Author(s), 2019

Licensee PAGEPress, Italy

Monaldi Archives for Chest Disease 2019; 89:1053

doi: 10.4081/monaldi.2019.1053

This article is distributed under the terms of the Creative Commons Attribution Noncommercial License (by-nc 4.0) which permits any noncommercial use, distribution, and reproduction in any medium, provided the original author(s) and source are credited.
March 2014 to March 2015 by Doppler echocardiography. Among the 295 subjects evaluated, 217 (73.6\%) had normal LV diastolic function and represented the final study population. At 1-year follow-up, 53 of 217 patients (24\%) developed LVDD, which was of degree I (mild dysfunction) in all of them. By multivariate logistic regression analysis, lower E/A ratio of transmitral flow (ratio between the peak velocity of early diastolic "E" wave and late diastolic "A" wave of transmitral flow) was independently associated with new-onset LVDD (OR 0.17 [CI 0.09-0.57]), together with older age and higher systolic blood pressure. In a clinical predictive model derived from multivariate analysis, the new-onset LVDD rate event ranged from $0 \%$ (patients without any factor) to $75 \%$ (patients in whom the three predictors coexisted). A significant portion of patients with RA without overt cardiac disease develop LVDD at 1-year follow-up. This condition can be predicted by a simple clinical model which could improve the clinical management and the prognostic stratification of patients with RA.

\section{Introduction}

Rheumatoid arthritis (RA) is associated with increased cardiovascular morbidity and mortality [1-6]. In particular, patients with RA have an approximately 2-fold higher incidence of congestive heart failure (CHF), compared to the general population $[7,8]$. Several studies report that left ventricular (LV) diastolic function is impaired in a consistent portion of patients with RA without clinically evident cardiac disease [9-23], thus suggesting that subclinical LV diastolic dysfunction (LVDD) is an early predictor of subsequent overt CHF. LVDD is the result of mechanical and structural abnormalities such as interstitial fibrosis, impaired myocyte relaxation, decreased distensibility [24,25], and it is ordinarily recognized in clinical practice by standard transthoracic Doppler echocardiography. In RA patients, LVDD has been variously described as reduced E/A ratio, prolonged isovolumetric relaxation time, larger left atrial size and/or high systolic pulmonary artery pressure [9-23]. However, very little is available on the incidence and the predictors of new onset LVDD in RA and conflicting data exist on the relationship between RA disease duration and alteration of LV diastolic function [11,12,17-20,26]. Recently, Davis et al. evaluated longitudinal changes in cardiac structure and function of 160 patients with RA compared with 1391 non-RA persons used as controls. They demonstrated that subclinical changes in diastolic function occurred early and the 
rates of these changes were significantly higher in patients with RA over five years than in the general population [27].

Accordingly, this study was conceived to assess the factors related to new-onset LVDD and its incidence at 1-year follow-up in a large cohort of asymptomatic RA patients without history of cardiac disease and normal LV diastolic function at baseline echocardiographic evaluation.

\section{Materials and Methods}

\section{Study population}

Study participants were 295 adults with RA diagnosed according to the American College of Rheumatology criteria [28], without history of cardiac disease. They were recruited from March 2014 to March 2015 and represented the whole RA population surveyed by the Division of Rheumatology of the Verona University where they underwent echocardiographic, clinical and laboratory evaluations. All subjects were free of symptoms and clinical signs of cardiac disease at enrollment. Exclusion criteria were a history of myocardial infarction, myocarditis or $\mathrm{CHF}$, coronary heart disease diagnosed by clinical, electrocardiographic evaluation at rest and by the results of exercise/scintigraphy/echo-stress test, alcoholic cardiomyopathy, primary hypertrophic cardiomyopathy, asymptomatic known LV systolic dysfunction, prior myocardial revascularization, significant valve heart disease, atrial fibrillation.

Among the 295 patients with RA, 78 patients (26\%) were excluded because LVDD was already present at echocardiographic baseline evaluation. Thus, the remaining 217 subjects with normal LV diastolic function represented the final study population. They were re-evaluated after one year by Doppler echocardiography (Figure 1). All patients gave written informed consent and the
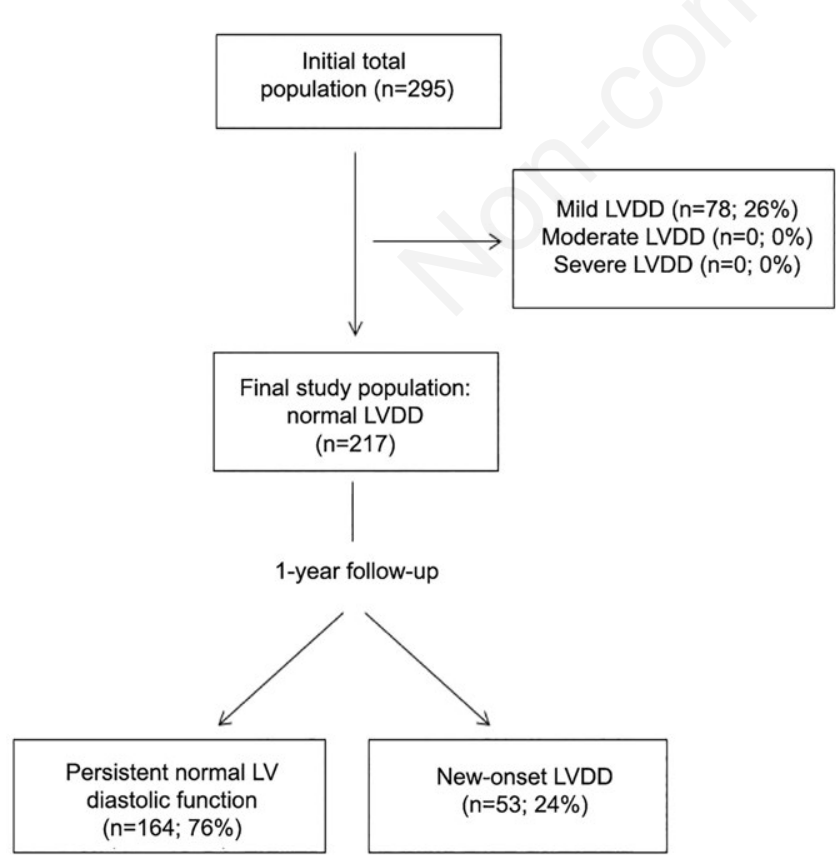

Figure 1. Study design. Flow chart of patient's selection showing the number of subjects included in the study and the classification of left ventricular diastolic dysfunction (LVDD). study was approved by Ethical Committees in all participating Centers. The study protocol conforms to the ethical guidelines of the Declaration of Helsinki as revised in 2000.

\section{Definitions}

Hypertension was defined as a systolic blood pressure of at least $140 \mathrm{mmHg}$ and/or a diastolic blood pressure of at least 90 $\mathrm{mmHg}$, and/or pharmacologically treated blood pressure of unknown cause. Obesity was diagnosed if patients had body mass index $\geq 30 \mathrm{~kg} / \mathrm{m}^{2}$. Dyslipidemia was defined as levels of total serum cholesterol above $190 \mathrm{mg} / \mathrm{dl}$ and/or triglycerides above 150 $\mathrm{mg} / \mathrm{dl}$, or pharmacologically treated high lipid serum levels. To assess renal function, we considered the glomerular filtration rate (GFR) estimated with the CKD-EPI equation.

\section{Echocardiography}

All Doppler-echocardiographic studies were performed using Alpha Esaote machine (Florence, Italy) equipped with a 2.5-3.5 $\mathrm{MHz}$ annular-array transducer by experienced cardiologists who followed a standardized protocol. Images were stored on CD or MO disks and forwarded for final interpretation at the Echocardiography Core Laboratory at Villa Bianca Hospital of Trento, Italy. Sonographers (GC, FO) were blinded to clinical data. LV chamber dimensions and wall thicknesses were measured by the American Society of Echocardiography guidelines and LV mass was calculated using a validated formula [29]. LV mass was normalized for height to the 2.7 power and LV hypertrophy was defined as LV mass $\geq 49.2 \mathrm{~g} / \mathrm{m}^{2.7}$ for men and $\geq 46.7$ for women [30]. Relative wall thickness was calculated as the $2 *$ end-diastolic ratio posterior wall thickness/LV diameter and indicated concentric LV geometry if $\geq 0.43$ (the 97.5 percentile in a normal population) [31]. LV end-diastolic and end-systolic volumes were measured by the biplane method of disks from 2D apical 4 chamber +2 chamber views and used to calculate LV ejection fraction (LVEF), defined as reduced if $<50 \%$.

Transmitral and pulmonary vein pulsed wave Doppler curves and early diastolic Tissue Doppler velocity of mitral annulus (E', expressed as mean of 4 measurements obtained in septal, lateral, inferior and anterior mitral annular position) were assessed according to the recommendations of the American Society of Echocardiography [32]. Early diastolic velocity of transmitral flow (E) was divided by E' and used to classify LV diastolic function together with other parameters including E/A ratio of transmitral flow (ratio between the peak velocity of early diastolic "E" wave and late diastolic "A" wave of transmitral flow), deceleration time of $\mathrm{E}$ and the difference in duration of atrial wave on pulmonary vein flow and atrial wave on transmitral flow) in 4 degrees as proposed by Redfield et al. [33] and according to the progression of diastolic dysfunction: degree $\mathrm{I}=$ normal; degree $\mathrm{II}=$ mild dysfunction (impaired relaxation without evidence of increased LV filling pressures; degree III=moderate dysfunction (impaired relaxation associated with mild to moderate elevation of LV filling pressures); degree $I V=$ severe dysfunction (restrictive physiology with highly increased filling pressures). Pulmonary capillary wedge pressure (PCWP) was non-invasively estimated by the formula validated by Nagueh et al. [34]. Maximal left atrial volume was also computed from 2D apical 4-chamber view using the area length method and was normalized for body surface area. Left atrial systolic force was calculated using the formula validated by Manning and coworkers [35]. 


\section{Statistical analysis}

Data are reported as mean values \pm 1 standard deviation (medians and interquartile ranges for variables deviating from normality) or percentages. Unpaired Student's $t$-test and $\chi^{2}$ statistics were used for descriptive statistics. Between-group comparisons of categorical and continuous variables were performed by $\chi^{2}$ test and analysis of variance (ANOVA) with comparison between each group by Scheffé's test for unequal sample, as appropriate. The study population was stratified by the development of new-onset LVDD during follow-up. Variables that were significantly related to the development of this condition in univariate tests $(\mathrm{p}<0.01)$ were included in the multivariate models. Two multivariate logistic regression analyses were performed to identify the independent predictors of new-onset LVDD detected during follow-up. In the first one, only clinical variables were considered. The variables included in this analysis were: age, systolic blood pressure, history of hypertension, serum protein $\mathrm{C}$ reactive levels. In the second one, clinical and echocardiographic variables were taken into account. The following variables were included in this model: age, systolic blood pressure, E/A ratio of transmitral flow, concentric LV geometry, peak E', left atrial ejection force. The independent predictors of new-onset LVDD emerging by multiple logistic regression analysis were subsequently handled as categorical variables using cut-points derived by specific receiver operating characteristic (ROC) curve analyses and combined to find a multivariable model which better predicted new-onset LVDD among RA patients. The ROC curves were compared using the $\mathrm{z}$ statistics with the curves resulting by each single variable, without correction for multiple comparisons, to lessen the probability of type 1 error [36]. All analyses were performed using statistical package SPSS 19.0 (SPSS Inc. Chicago, IL, USA) and statistical significance was identified by two-tailed $\mathrm{p}<0.05$.

\section{Results}

The study population consisted of 217 patients with RA (mean age of $57 \pm 13$ years, $67 \%$ women) whose principal features are shown in Table 1. They had a prevalence of hypertension of $43 \%$ and dyslipidemia of $63 \%$, a long history of RA disease (mean $14 \pm 10$ years), a high number of joints involved (mean $11 \pm 9$ ), $6 \%$ of them showed extra-articular manifestations of RA, the disease activity was high in $15 \%$ of cases. Looking at the echocardiographic variables, $63 \%$ of patients had concentric LV geometry, LVEF was normal in all patients as well as PCWP (mean value $10 \pm 2$ $\mathrm{mmHg}$ ), confirming the presence of a compensated hemodynamic state in each enrolled subject (Table 2). Echocardiographic examination at 1-year follow-up showed that 164 patients (76\%) maintained a normal LV diastolic function, while the remaining 53 (24\%) developed LVDD, which was of degree I (mild dysfunction) in all of them

\section{Baseline features of new-onset LVDD patients}

Patients with new-onset LVDD were older, had higher systolic blood pressures, higher prevalence of history of arterial hypertension and higher serum protein $\mathrm{C}$ reactive levels than those with persistent normal LV diastolic function (Table 3). Body mass index, prevalence of female gender, renal function, lipid and glyco- metabolic profile were similar between the two study groups. Similarly, no difference in pharmacological treatment for the control of the cardiovascular risk factors existed between the two groups. Considering the echocardiographic variables, the patients with new-onset LVDD had a higher prevalence of LV concentric geometry, lower E/A ratio of transmitral flow, higher E/E' ratio, larger maximal left atrial volume and higher left atrial systolic

Table 1. Main clinical characteristics of the 217 study patients. Variables Study population

\begin{tabular}{|c|c|}
\hline \multicolumn{2}{|l|}{ Clinical } \\
\hline Age (yrs) & $57 \pm 13$ \\
\hline Female gender (\%) & 67 \\
\hline Body Mass index $\left(\mathrm{kg} / \mathrm{m}^{2}\right)$ & $25.0 \pm 4.3$ \\
\hline Waist circumference (cm) & $90 \pm 13$ \\
\hline Obese $(\%)$ & 10 \\
\hline Hypertension (\%) & 43 \\
\hline Systolic blood pressure (mmHg) & $131 \pm 17$ \\
\hline Diastolic blood pressure (mmHg) & $81 \pm 9$ \\
\hline Dyslipidemia (\%) & 63 \\
\hline Active smoker (\%) & 39 \\
\hline Diabetes mellitus (\%) & 8 \\
\hline Heart rate (beats/min) & $70 \pm 11$ \\
\hline Duration of rheumatoid arthritis (yrs) & $14 \pm 10$ \\
\hline Number of joints involved & $11 \pm 10$ \\
\hline Extra-articular manifestations (\%) & 6 \\
\hline High activity of disease (\%) & 15 \\
\hline Clinical disease activity index & $10 \pm 8$ \\
\hline \multicolumn{2}{|l|}{ Laboratory } \\
\hline Hemoglobin (gr/dl) & $13.9 \pm 1.4$ \\
\hline GFR (ml/min/1.73m²) & $94 \pm 23$ \\
\hline $\mathrm{GFR}<60 \mathrm{ml} / \mathrm{min} / 1.73 \mathrm{~m}^{2}(\%)$ & 5 \\
\hline Total cholesterol (mg/dl) (median IQR) & $208(184-239)$ \\
\hline Cholesterol LDL (mg/dl) (median IQR) & $121(97.5-139)$ \\
\hline Triglycerides (mg/dl) (median IQR) & $101(71-134)$ \\
\hline $\mathrm{C}$ reactive protein (mg/l) (median IQR) & $1.6(0.6-3.5)$ \\
\hline Rheumatoid factor positive (\%) & 42 \\
\hline Cyclic citrullinated peptide positive (\%) & 40 \\
\hline \multicolumn{2}{|l|}{ Pharmacological treatment } \\
\hline Betablockers (\%) & 15 \\
\hline ACEi / ARB (\%) & 26 \\
\hline Diuretics (\%) & 13 \\
\hline Calcium antagonists (\%) & 11 \\
\hline Anti-platelets agents (\%) & 14 \\
\hline Statins $(\%)$ & 23 \\
\hline NSAIDs (\%) & 34 \\
\hline Metotrexate (\%) & 44 \\
\hline Hydroxychloroquine (\%) & 11 \\
\hline Immunomodulatory and anti-cytotoxic agents (\%) & 69 \\
\hline Corticosteroids (\%) & 42 \\
\hline
\end{tabular}

ACEi, angiotensin-converting enzyme inhibitors; ARB, angiotensin T1 receptor blockers; GFR, glomerular filtration rate; NSAIDs, non-steroidal anti-inflammatory drugs. Values are indicated as mean \pm SD 
force than the counterparts with persistent normal LV diastolic function (Table 3).

\section{Predictors of new-onset LVDD}

To identify the predictors of new-onset LVDD, two multivariate logistic regression analyses were performed (Table 4). In a first model, which encompassed only clinical variables (Table 4, model 1), older age was closely associated with new-onset LVDD together with higher systolic blood pressure and history of hypertension, while no association was found with serum protein $\mathrm{C}$ reactive levels. In a second model, both clinical and echocardiographic variables were considered. Lower E/A ratio of transmitral flow emerged as independent condition associated with new-onset LVDD (OR 0.17, CI 0.09-0.57), together with older age and higher systolic blood pressure (Table 4, model 2). No independent association was found between the presence of new-onset LVDD and the other variables considered in the analysis including concentric LV geometry, peak E', left atrial systolic force.

\section{Clinical predictive model for new-onset LVDD}

A clinical model for the prediction of new-onset LVDD was derived by the results of the multivariate regression analysis and included age, systolic blood pressure and E/A ratio of transmitral flow. ROC curve analyses showed that the best cut-off value for age was 57 years, $131 \mathrm{mmHg}$ for systolic blood pressure and 0.96 for E/A ratio of transmitral flow. Figure 2 shows the distribution of RA patients who developed LVDD according to the number of the factors considered in the model. The rate of new-onset LVDD events ranged from $0 \%$ in patients without any factor to $75 \%$ in those in whom the three factors coexisted. Figure 3 shows the accuracy for the prediction of new-onset LVDD when the three variables were considered individually or as elements of the predictive model.

\section{Discussion}

This prospective study provides new data regarding the incidence and the predictors of new-onset LVDD in individuals with RA and no history of cardiac disease. A first result of our research is that

Table 2. Echocardiographic characteristics of 217 study patients.

\begin{tabular}{|c|c|}
\hline Variables & Study population \\
\hline LV end-diastolic diameter $\left(\mathrm{cm} / \mathrm{m}^{2}\right)$ & $2.6 \pm 0.3$ \\
\hline LV end-diastolic volume $\left(\mathrm{ml} / \mathrm{m}^{2}\right)$ & $48 \pm 10$ \\
\hline LV Relative wall thickness & $0.45 \pm 0.07$ \\
\hline Concentric LV geometry (\%) & 63 \\
\hline LV mass index $\left(\mathrm{g} / \mathrm{m}^{2.7}\right)$ & $43 \pm 11$ \\
\hline LV ejection fraction (\%) & $66 \pm 6$ \\
\hline \multicolumn{2}{|l|}{ Transmitral flow } \\
\hline Peak E wave velocity $(\mathrm{cm} / \mathrm{s})$ & $72 \pm 15$ \\
\hline Peak A wave velocity $(\mathrm{cm} / \mathrm{s})$ & $70 \pm 17$ \\
\hline A wave duration (ms) & $125 \pm 22$ \\
\hline E wave deceleration time (ms) & $203 \pm 51$ \\
\hline E wave deceleration rate & $3.7 \pm 1$ \\
\hline E/A ratio & $1.08 \pm 0.35$ \\
\hline Peak E' (cm/s) & $11 \pm 3$ \\
\hline E/E' ratio & $6.6 \pm 1.8$ \\
\hline \multicolumn{2}{|l|}{ Pulmonary venous flow } \\
\hline Peak systolic velocity (cm/s) & $60 \pm 13$ \\
\hline Peak diastolic velocity $(\mathrm{cm} / \mathrm{s})$ & $45 \pm 10$ \\
\hline Systolic fraction (\%) & $57 \pm 5$ \\
\hline A wave duration (ms) & $103 \pm 19$ \\
\hline $\mathrm{Z}-\mathrm{A}(\mathrm{ms})$ & 22 \\
\hline PCWP (mmHg) & $10 \pm 2$ \\
\hline Maximal left atrial volume $\left(\mathrm{ml} / \mathrm{m}^{2}\right)$ & $19 \pm 7$ \\
\hline Left atrial ejection force $\left(\mathrm{kdynes} / \mathrm{cm}^{2}\right)$ & $11.1 \pm 5.9$ \\
\hline PAPs (mmHg) & $26 \pm 9$ \\
\hline
\end{tabular}

Table 3. Clinical and echocardiographic variables significantly different between patients with persistent normal left ventricular diastolic function and those who developed diastolic dysfunction during follow-up.

\begin{tabular}{|c|c|c|c|}
\hline Variables & $\begin{array}{l}\text { Persistent normal } \\
\text { diastolic function } \\
\text { ( } \mathrm{n}=164 \text { patients) }\end{array}$ & $\begin{array}{c}\text { New-onset } \\
\text { diastolic dysfunction } \\
(\mathrm{n}=53 \text { patients })\end{array}$ & p \\
\hline Age (yrs) & $53 \pm 11$ & $63 \pm 8$ & $<0.001$ \\
\hline Systolic blood pressure (mmHg) & $130 \pm 15$ & $142 \pm 17$ & $<0.001$ \\
\hline Hypertension (\%) & 33 & 71 & $<0.001$ \\
\hline $\mathrm{C}$ reactive protein (mg/l) (median IQR) & $1.43(0.76-3.00)$ & $3.15(0.60-7.00)$ & $<0.001$ \\
\hline LV Relative wall thickness & $0.45 \pm 0.06$ & $0.49 \pm 0.07$ & $=0.01$ \\
\hline Maximal left atrial volume (ml/m²) & $17 \pm 5$ & $20 \pm 4$ & $=0.02$ \\
\hline Peak A wave velocity of transmitral flow $(\mathrm{cm} / \mathrm{s})$ & $65.9 \pm 13.5$ & $79.9 \pm 17.5$ & $<0.001$ \\
\hline E / A ratio of transmitral flow & $1.11 \pm 0.28$ & $0.89 \pm 0.13$ & $<0.001$ \\
\hline E/E' ratio & $6.4 \pm 1.4$ & $7.2 \pm 2.1$ & $=0.02$ \\
\hline Peak E' $(\mathrm{cm} / \mathrm{s})$ & $11 \pm 2$ & $10 \pm 2$ & $=0.01$ \\
\hline Pulmonary capillary wedge pressure (mmHg) & $9.8 \pm 1.7$ & $10.8 \pm 2.6$ & $=0.02$ \\
\hline Left atrial systolic force $\left(\mathrm{kdynes} / \mathrm{cm}^{2}\right)$ & $10.4 \pm 5.6$ & $14.7 \pm 7.4$ & $<0.001$ \\
\hline
\end{tabular}

Values are indicated as mean \pm SD 
approximately a quarter of patients with RA developed new-onset LVDD at 1-year follow-up. Several studies have previously analyzed LV diastolic function in these patients [9-23], as well as in those with other systemic inflammatory diseases [37], but no data was available on the incidence of new-onset LVDD in RA disease; thus, this has to be considered a new and original finding. Similarly, the prognosticators of this phenomenon are unknown. This issue has been investigated in detail in our study. In particular, we demonstrated that a lower E/A ratio of transmitral flow was the strongest independent condition related to new-onset LVDD together with older age and higher systolic blood pressure. Patients who developed newonset LVDD had a mean value of E/A ratio of transmitral flow at baseline evaluation of 0.89 . This value was very close to that indicated by Redfied et al. $(\mathrm{E} / \mathrm{A}=0.75)$ [33], as well as that more recently reported by Nagueh et al. $(\mathrm{E} / \mathrm{A}=0.80)$ in the ASE recommendations for the evaluation of LV diastolic function by echocardiography [32] as cut-off for identifying grade I LVDD. Our evidence that a lower E/A ratio of transmitral flow may predict the development of newonset LVDD seems to indicate the presence of a chronic pathophysiological course of LV diastolic function that slowly progresses during the time and can be followed by echocardiography. Several studies have analyzed the relationship between E/A ratio and RA disease duration and activity [11,12,17-20,26,27], based on the hypothesis that an ongoing subclinical myocardial inflammatory process could impact LV myocardial function. These analyses, however, led to conflicting results. In our experience, no association was found between the development of LVDD and any baseline clinical parameter of RA disease. A second predictor of new-onset LVDD was

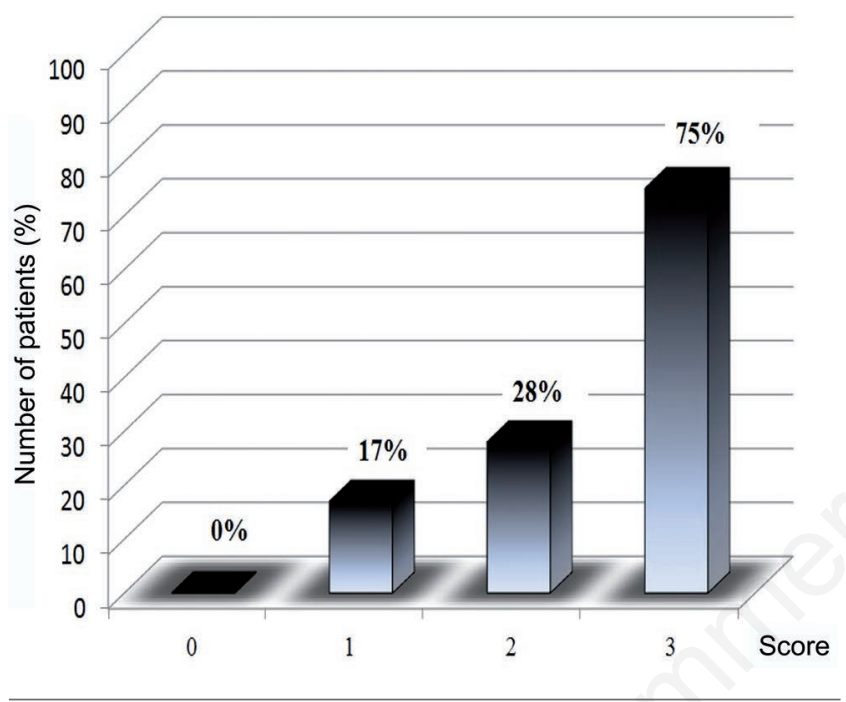

Figure 2. Distribution of rheumatoid arthritis (RA) patients who developed left ventricular diastolic dysfunction (LVDD) according to the number of the factors considered in the model. The rate of new-onset LVDD events ranged from $0 \%$ in patients without any factor to $75 \%$ in those in whom the three factors coexisted.

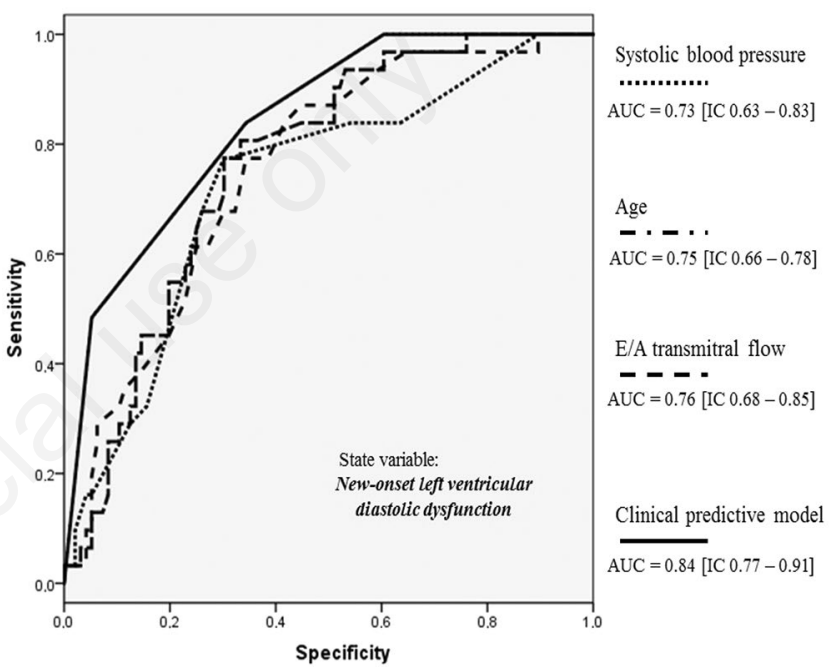

Figure 3. Accuracy for the prediction of new-onset left ventricular diastolic dysfunction (LVDD) when the three variables were considered individually or as elements of the predictive model.

Table 4. Variables independently associated with new-onset diastolic dysfunction recognized at 1-year follow up. Multivariate logistic regression analyses.

\begin{tabular}{|c|c|c|c|}
\hline \multicolumn{4}{|c|}{ Clinical model (1) } \\
\hline Variables & \multicolumn{3}{|c|}{ Confidence intervals } \\
\hline Systolic blood pressure (mmHg) & 1.03 & $1.00-1.07$ & $=0.02$ \\
\hline Age (yrs) & 1.06 & $1.00-1.11$ & $=0.04$ \\
\hline Hypertension (\%) & 2.98 & $1.06-8.40$ & $=0.04$ \\
\hline C reactive protein $(\mathrm{mg} / \mathrm{l})$ & 1.08 & $0.99-1.16$ & $=0.05$ \\
\hline \multicolumn{4}{|c|}{ Clinical + echocardiographic model (2) } \\
\hline E / A ratio of transmitral flow & 0.17 & $0.09-0.57$ & $=0.004$ \\
\hline Age (yrs) & 1.07 & $1.01-1.15$ & $=0.02$ \\
\hline Systolic blood pressure (mmHg) & 1.04 & $1.00-1.07$ & $=0.03$ \\
\hline Concentric left ventricular geometry (\%) & 1.81 & $0.50-6.49$ & $=0.36$ \\
\hline Peak E' (cm/s) & 1.18 & $0.87-1.59$ & $=0.29$ \\
\hline Left atrial ejection force (kdynes/cm²) & 0.99 & $0.92-1.08$ & $=0.95$ \\
\hline
\end{tabular}


older age. The progressive impairment of LV diastolic function with age is well known [38]. As a matter of fact, normal aging is associated with increased LV stiffness and slowing of myocardial relaxation. In our study, however, the mean age of the patients who developed new onset LVDD was 63 years and ROC curve analysis showed that the best cut-off value identifying the RA patients at higher risk for new onset LVDD was 57 years, corresponding to a middle-aged population. This finding has a clinical relevance and is in line with that reported by Montecucco et al. [18] and the more recent study of Davis et al. [27] which demonstrated that LVDD was observed at a younger age in the RA patients compared with the controls, suggesting a much earlier deterioration of diastolic function in the former. A third predictor of new-onset LVDD was higher systolic blood pressure. This was an expected finding, that accords with the well-established notion that hypertension leads to LVDD by increasing interstitial fibrosis, disturbance of calcium homeostasis and increased deposition of collagen [39]. Interestingly, in our study, the mean systolic blood pressure of patients who had new onset LVDD was $142 \mathrm{mmHg}$, a value just a little bit higher than that considered as normal, and the risk for developing this condition significantly increased over $131 \mathrm{mmHg}$ (as emerged by ROC curve analysis), a value within the range of normality of blood pressure. The present data lead to speculate that, in RA patients the optimization of systolic blood pressure control could reduce the risk of developing LVDD. Such hypothesis represents an intriguing challenge that should be tested by randomized trials specifically designed for this purpose. A final consideration regards the clinical predictive model for newonset LVDD which emerged by the ROC curve analyses. We built this model with the attempt to identify patients at high risk for developing LVDD during time. The accuracy of the model for this purpose is moderate (sensitivity $68 \%$; specificity $65 \%$ ). However, the present model has almighty negative prediction value. In fact, none of the patients without predictors of new-onset LVDD developed this condition during FU.

\section{Study limitations and strengths}

The main limitation of the present investigation is that LVDD was assessed by echocardiography, while no invasive hemodynamic data were available. However, Grant et al. [40] recently demonstrated that echocardiographic grading of LV diastolic function is significantly related to invasive hemodynamics, even if their relationship is modest. Furthermore, our findings do not take into consideration the possible effects of some pharmacological or nonpharmacological treatment for RA disease or hypertension on LV diastolic function. These conditions do not allow to precisely assess the pure impact of RA in the development of new-onset LVDD. Finally, no prognostic information was provided.

Strengths of our study consist of its prospective design, a large number of participants of both genders who were consecutively enrolled, the comprehensive nature of the dataset and the systematic approach to the study of left ventricular diastolic function, not only based on the Doppler indexes, but integrating Doppler patterns with other echo-parameters [41].

\section{Clinical implications and conclusions}

LVDD is a complex phenomenon that depends on a variety of factors and has been recognized as a primary cause of CHF. In this study we demonstrated that a significant portion of patients with RA without overt cardiac disease and normal LV diastolic function, develops new-onset LVDD at 1-year follow-up. This condition can be predicted by a simple clinical model, which could improve the clinical management and the prognostic stratification of patients with RA.

\section{References}

1. Mutru O, Laakso M, Isomaki H, Koota K. Cardiovascular mortality in patients with rheumatoid arthritis. Cardiology 1989;76:71-7.

2. Bacon PA, Townend JN. Nails in the coffin: increasing evidence for the role of rheumatic disease in the cardiovascular mortality of rheumatoid arthritis. Arthritis Rheum 2001;44:2707-10.

3. Solomon DH, Karlson EW, Rimm EB, et al. Cardiovascular mortality and morbidity in women diagnosed with rheumatoid arthritis. Circulation 2003;107:1303-7.

4. Dougados M, Betteridge N, Burmester GR, et al. EULAR standardized operating procedures for the elaboration, evaluation, dissemination, and implementation of recommendations endorsed by the EULAR standing committees. Ann Rheum Dis 2004;63:1172-6.

5. Avina-Zubieta JA, Choi HK, Sadatsafavi M, et al. Risk of cardiovascular mortality in patients with rheumatoid arthritis: a meta-analysis of observational studies. Arthritis Rheum 2008;59:1690-7.

6. Gonzalez A, Maradit Kremers H, Crowson CS, et al. The widening mortality gap between rheumatoid arthritis patients and the general population. Arthritis Rheum 2007;56:3583-7.

7. Nicola PJ, Maradit-Kremers H, Roger VL, et al. The risk of congestive heart failure in rheumatoid arthritis: a populationbased study over 46 years. Arthritis Rheum 2005;52:412-20.

8. Nicola PJ, Crowson CS, Maradit-Kremers H, et al. Contribution of congestive heart failure and ischemic heart disease to excess mortality in rheumatoid arthritis. Arthritis Rheum 2006;54:60-7.

9. Liang KP, Myasoedova E, Crowson CS, et al. Increased prevalence of diastolic dysfunction in rheumatoid arthritis. Ann Rheum Dis 2010;69:1665-70.

10. Birdane A, Korkmaz C, Ata N, e al. Tissue Doppler imaging in the evaluation of the left and right ventricular diastolic functions in rheumatoid arthritis. Echocardiography 2007;24:485-93.

11. Rexhepaj N, Bajraktari G, Berisha I, et al. Left and right ventricular diastolic functions in patients with rheumatoid arthritis without clinically evident cardiovascular disease. Int J Clin Pract 2006;60:683-8.

12. Levendoglu F, Temizhan A, Ugurlu H, et al. Ventricular function abnormalities in active rheumatoid arthritis: a Doppler echocardiographic study. Rheumatol Int 2004;24:141-6.

13. Alpaslan M, Onrat E, Evcik D. Doppler echocardiographic evaluation of ventricular function in patients with rheumatoid arthritis. Clin Rheumatol 2003;22:84-8.

14. Crowson CS, Myasoedova E, Davis JM 3rd, et al. Use of B-type natriuretic peptide as a screening tool for left ventricular diastolic dysfunction in rheumatoid arthritis patients without clinical cardiovascular disease. Arthritis Care Res 2011;63:729-34.

15. Marasovic-Krstulovic D, Martinovic-Kaliterna D, Fabijanic D, Morovic-Vergles J. Are the anti-cyclic citrullinated peptide antibodies independent predictors of myocardial involvement in patients with active rheumatoid arthritis? Rheumatology 2011;50:1505-12. 
16. Rudominer RL, Roman MJ, Devereux RB, et al. Independent association of rheumatoid arthritis with increased left ventricular mass but not with reduced ejection fraction. Arthritis Rheum 2009;60:22-9.

17. Yazici D, Tokay S, Aydin S, et al. Echocardiographic evaluation of cardiac diastolic function in patients with rheumatoid arthritis: 5 years of follow-up. Clin Rheumatol 2008;27:647-50.

18. Montecucco C, Gobbi G, Perlini S, et al. Impaired diastolic function in active rheumatoid arthritis: relationship with disease duration. Clin Exp Rheumatol 1999;17:407-12.

19. Canturk F, Yazici M, Alayli G, et al. Combined use of propagation velocity and intraventricular dispersion of $\mathrm{E}$ wave velocity for the evaluation of diastolic functions in patients with rheumatoid arthritis. Int J Cardiovasc Imaging 2006;22:369-76.

20. Arslan S, Bozkurt E, Sari RA, Erol MK. Diastolic function abnormalities in active rheumatoid arthritis evaluation by conventional Doppler and tissue Doppler: relation with duration of disease. Clin Rheumatol 2006;25:294-9.

21. Gonzalez-Juanatey C, Testa A, Garcia-Castelo A, et al. Echocardiographic and Doppler findings in long-term treated rheumatoid arthritis patients without clinically evident cardiovascular disease. Semin Arthritis Rheum 2004;33:231-8.

22. Di Franco M, Paradiso M, Mammarella A, et al. Diastolic function abnormalities in rheumatoid arthritis: evaluation by echo Doppler transmitral flow and pulmonary venous flow. Relation with duration of disease. Ann Rheum Dis 2000;59:227-9.

23. Mustonen J, Laakso M, Hirvonen T, et al. Abnormalities in left ventricular diastolic function in male patients with rheumatoid arthritis without clinically evident cardiovascular disease. Eur J Clin Invest. 1993;23:246-53.

24. Fukuta H, Little WC. Diagnosis of diastolic heart failure. Curr Cardiol Rep 2007;9:224-8.

25. Segers VF, De Keulenar GW. Patophysiology of diastolic dysfunction in chronic heart failure. Future Cardiol 2013;9:711-20.

26. Abdul Muizz AM, Mohd Shahrir MS, Sazliyana S, et al. A cross-sectional study of diastolic dysfunction in rheumatoid arthritis and its association with disease activity. Int J Rheum Dis. 2011;14:18-30.

27. Davis JM 3rd, Lin G, Oh JK, et al. Five-year changes in cardiac structure and function in patients with rheumatoid arthritis compared with the general population. Int J Cardiol. 2017 Mar 31 doi: 10.1016/j.ijcard.2017.03.108.

28. Arnett FC, Edworthy SM, Bloch DA, et al. The American Rheumatism Association 1987 revised criteria for the classification of rheumatoid arthritis. Arthritis Rheum 1988;31:315-24.

29. Devereux RB, Alonso DR, Lutas EM, et al. Echocardiographic assessment of left ventricular hypertrophy: comparison to necropsy findings. Am J Cardiol. 1986;57:450-8.

30. de Simone G, Devereux RB, Daniels SR, et al. Effect of growth on variability of left ventricular mass: assessment of allometric signals in adults and children and their capacity to predict cardiovascular risk. J Am Coll Cardiol 1995;25:1056-62.

31. de Simone G, Daniels SR, Kimball TR, et al. Evaluation of concentric left ventricular geometry in humans: evidence for agerelated systematic underestimation. Hypertension 2005;45:64-8.

32. Nagueh SF, Smiseth OA, Appleton CP, et al. Recommendations for the evaluation of left ventricular diastolic function by echocardiography: An update from the American Society of Echocardiography and the European Association of Cardiovascular Imaging. $\mathrm{J}$ Am Soc Echocardiogr 2016;29:277-314.

33. Redfield MM, Jacobsen SJ, Burnett JC Jr, et al. Burden of systolic and diastolic ventricular dysfunction in the community: appreciating the scope of the heart failure epidemic. JAMA 2003;289:194-202.

34. Nagueh SF, Middleton KJ, Kopelen HA, et al. Doppler tissue imaging: a noninvasive technique for evaluation of left ventricular relaxation and estimation of filling pressures. J Am Coll Cardiol 1997;30:1527-33.

35. Manning WJ, Silverman DI, Katz SE, Douglas PS. Atrial ejection force: A noninvasive assessment of atrial systolic function. J Am Coll Cardiol 1993;22:221-5.

36. Hanley JA, McNeil BJ. The meaning and use of the area under a Receiver Operating characteristic (ROC) curve. Radiology 1982;143:29-36.

37. Gorga E, Scodro M, Valentini F, et al. Echocardiographic evaluation of diastolic dysfunction in young and healthy patients with psoriasis: A case-control study. Monaldi Arch Chest Dis 2018;88:934.

38. Sagie A, Benjamin EJ, Galderisi M, et al. Reference values for Doppler indexes of left ventricular diastolic filling in the elderly. J Am Soc Echocardiogr 1993;6:570-6.

39. Ouzounian M, Lee DS, Liu PP. Diastolic heart failure: mechanisms and controversies. Nat Clin Pract Cardiovasc Med. 2008;5:375-86.

40. Grant AD, Negishi K, Negishi T, et al. Grading diastolic function by echocardiography: hemodynamic validation of existing guidelines. Cardiovasc Ultrasound 2015;13:28.

41. Vizzardi E, Faggiano P, Chiari E, et al. [The study of left ventricular diastolic function by Doppler echocardiography: the essential for the clinician].[Article in Italian]. Monaldi Arch Chest Dis 2009;72:23-8. 
